\title{
Acquiring L2 phonemes and recognition of their allophonic variances
}

\author{
Mariko Kondo ${ }^{1}$, Takayuki Konishi ${ }^{2}$ \\ ${ }^{1}$ SILS \& GSICCS, Waseda University, Japan \\ ${ }^{2}$ GSICCS, Waseda University, Japan \\ https://doi.org/10.36505/ExLing-2018/09/0017/000350
}

\begin{abstract}
Japanese speakers have problems differentiating the English liquid consonants $/ 1 /$ and $/ \mathrm{r} /$, both in production and perception. However, recent studies have shown that Japanese speakers can identify English approximant $[\mathrm{I}]$ because it forms a new phonetic category. We trained Japanese speakers with American accent /r/ ([I] $]$ ) and / / , and tested them with American and Scottish accented English; Scottish / $\mathrm{r} /$ is often realized as tap [r]. The results showed that Japanese speakers learned to discriminate American $/ \mathrm{r} /([\mathrm{I}])$ and $/ \mathrm{l} /$, but not Scottish / $\mathrm{r} /([\mathrm{C}])$ and $/ \mathrm{l} /$. The results imply that the Japanese speakers learned $[\mathrm{I}]$, but did not acquire the English phoneme /r/ and its allophones. Key words: L2 English acquisition, English liquids, acquisition of L2 allophones
\end{abstract}

\section{Introduction}

Japanese speakers have difficulty in differentiating /l/ and $/ \mathrm{r} /$ consonants (e.g. Takagi \& Mann 1995, Flege at al. 1996, Aoyama \& Flege 2011). Variations of both / $/$ / and / $\mathrm{r} /$ occur in Japanese, but they are not contrastive and so are considered as allophones of $/ \mathrm{r} /$, with the most common realization being alveolar tap [r]. However, recent studies (e.g. Flege et al. 1995, Guion et al. 2000, Aoyama et al. 2011, Hattori \& Iverson 2009) found that Japanese speakers could discriminate American English and Southern British $/ \mathrm{r} /$, because $/ \mathrm{r} /$ in these varieties is a postalveolar approximant $[\mathrm{x}]$ and is quite distinct from Japanese consonants, all of which lack lip rounding and tongue retraction. It means that [I] forms what the Speech Learning Model (Flege 1995) calls "a new phonetic category", and while Japanese speakers may not be able to discriminate English $/ 1 /$ and $/ \mathrm{r} /$ as separate phonemes, they can identify $[\mathrm{r}]$ as /r/ and other liquids as "not /r/", hence /l/ (Figure 3a).

However, problems arise with some varieties of English, e.g. Scottish English, which has both $/ 1 /$ and $/ \mathrm{r} /$, but the realizations of $/ \mathrm{r} /$ vary. Scottish English is rhotic and $/ \mathrm{r} /$ is retained in all positions where it occurs and may be realized as trill [r] tap [r] (e.g. Cruttenden 2014).

ExLing 2018: Proceedings of 9th Tutorial and Research Workshop on Experimental Linguistics, 28-30 August, Paris, Frannce 
The issue is that if Japanese speakers have acquired an English phoneme /r/ associated with the most common allophone of approximant $[\mathrm{I}]$, can they extend their knowledge of $/ \mathrm{r} /$ to different allophones in different accents, like native English speakers do? Also, can Japanese speakers differentiate tap $[\mathrm{r}]$ from $/ \mathrm{l} /$ even if their logic of ' $[\mathrm{I}]$ as /r/' and 'others as /1/' cannot be applied?

In this study, we investigated acquisition of an English approximant [I] by Japanese learners of English and assessed (1) if they can discriminate [x] from /1/, and (2) if they can apply their phonetic knowledge to other allophonic varieties of the sound, by being trained with American English, and then tested with American and Scottish accents.

\section{Experiments}

The subjects were 18 (10 male, 8 female) 17-18 year old native Japanese high school students from near Tokyo who had studied English for about 5 years and were taking an English class taught by one of the authors. None of them had lived abroad for more than a few weeks.

The students were trained on the liquid consonants, using audio-visual materials recorded by native American English speakers, and articulatory training by one of the authors. The training lasted for approximately 10 minutes in each lesson, once a week for 5 weeks. The training emphasized lip-rounding and tongue retraction of the $[\mathrm{I}]$ articulation, and alveolar and tongue-tip contact with lateral release for the $/ 1 /$. The students took three tests during the 5 weeks: (i) a pre-test in the $1^{\text {st }}$ week with a male American English speaker different from the training material speakers, and (ii) two post-tests in the $5^{\text {th }}$ week, one with a female American English speaker and the other with a male Scottish English speaker. The three tests were all two-alternative forced-choice identification tests of forty-five minimal pairs of words, contrasting only by $/ 1 /$ and $/ \mathrm{r} /$, i.e. 45 pairs $\times 2$ words $=90$ stimuli. The students had to choose the word they heard from pairs of words listed on the answer sheet: word initial (e.g. lead-read), consonant clusters (e.g. fly-fry), word medial (e.g. collect-correct) and word final (e.g. tool-tour). The 90 test words were randomly presented once, with a 5 second pause between stimuli.

\section{Results and discussion}

The students' English levels differed, so we compared the improvement ratio of their scores between the pre-test and the post-tests. The average pre-test score was $66.73 \%$, and the average scores of the American English and Scottish English post-tests were 77.78 and 67.35, 
Acquiring L2 phonemes and recognition of their allophonic variants 75

respectively (Figure 1). These data showed that the students' identification scores improved much more for American English than for Scottish English (Fig. 2).

The sensitive score (d') of the forced choice tests was calculated and the results are shown in Figure 3. One-way ANOVA (repeated) of the Pre-test and American post-test and Scottish post-test sensitivity scores showed a significant main effect $[\mathrm{F}(2,34)=21.01, \mathrm{p}<.001]$. Pairwise $t$ test with Bonferroni correction showed significant differences between the Pre-test and American accent Post-test, and between the American and Scottish accent Post-tests $(\mathrm{p}<.05)$. However, the difference between Pre-test and Scottish accent Post-test was not significant.
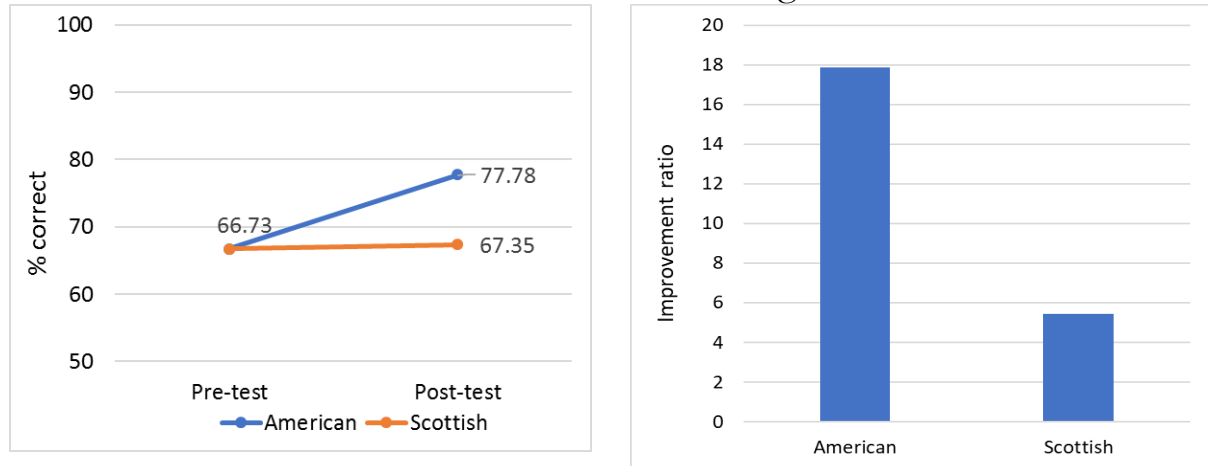

Figure 1. Average correct Figure 2. Average \% improvement identification for American and between pre- and post-test.

Scottish accents.

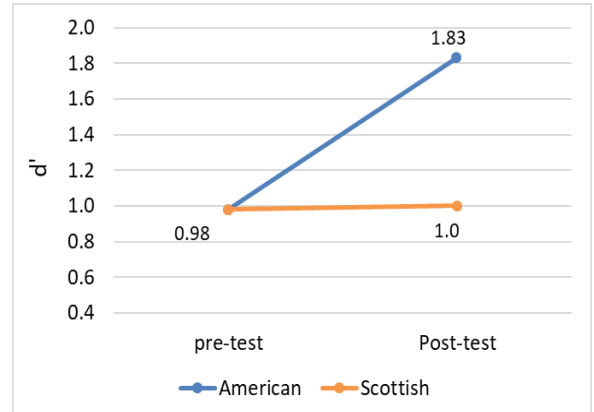

(a)

American English

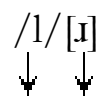

Japanese perception
Figure 3. Sensitivity index of identification for American and Scottish accents.

(b) Scottish English

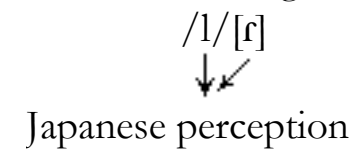

Figure 4. Perception of English liquids by Japanese speakers. $|\mathrm{I}|$ here represent a new phonetic category. 
The results showed that the Japanese speakers learned how to discriminate American English /1/ and /r/, but not Scottish /l/ and /r/. This may be because they could recognize the approximant $[\mathrm{I}]$ as a new phonetic category and discriminate it from /1/ which was categorized as Japanese /r/, as some previous studies have suggested (Figure 4(a)). Figure 3 shows that the sensitivity score (d') of the American accent Post-test was much higher than that for the Scottish accent Post-test. This result suggests that the Japanese students relied on the $[\mathrm{I}]$ as a cue to discriminate the liquids but not $/ 1 /$. Our Scottish English speaker used tap [r] much more than [I]. Therefore, in the Scottish English speech, both / $/$ and tap $[\mathrm{r}]$, which is the typical realization of Japanese $/ \mathrm{r} /$, were undifferentiated and were probably categorized as the same $/ \mathrm{r} /$ sound by the Japanese speakers (Figure 4(b)).

\section{Conclusions}

The results suggest that Japanese speakers can recognize approximant $[\mathrm{I}]$ and used it as a cue for discriminating $/ \mathrm{r} /$ from $/ 1 /$. However, they have not acquired $[\mathrm{I}]$ as a phoneme $/ \mathrm{r} /$, and therefore they cannot recognize its allophone $[\mathrm{r}]$ as the sound in the same category.

\section{References}

Aoyama, K., Flege, J.E. 2011. Effects of L2 Experience on Perception of English /r/ and /1/ by Native Japanese Speakers. Journ. Phonetic Society of Japan 15:3, 5-13.

Aoyama, K., Flege, J.E., Guion, S.G., Akahane-Yamada, R., Yamada, T. 2011. Perceived phonetic dissimilarity and L2 speech learning: the case of Japanese /r/ and English /1/ and /r/" Journal of Phonetics 32, 233-250.

Cruttenden, A. 2014. Gimson's Pronunciation of English ( $8^{\text {th }}$ ed.). Abingdon: Routledge.

Flege, J.E. 1995. Second language speech learning: Theory, findings, and problems. In Strange, W. (Ed.). Speech perception and linguistic experience: Issues in crosslanguage research 233-277. Timonium, MD: York Press.

Flege, J.E., Takagi, N., Mann, V. 1995. Japanese adults can learn to produce English $/ \mathrm{r} /$ and /1/ accurately. Language and Speech 38, 25-55.

Flege, J.E., Takagi, N., Mann, V. 1996. Lexical familiarity and English-language experience affect Japanese adults' perception of /r/ and /1/. JASA 99, 1161-1173.

Guion, S.G., Flege, J.E., Akahane-Yamada, R., Pruitt, J.C. 2000. An investigation of current models of second language speech perception: The case of Japanese adults' perception of English consonants. JASA 107, 2711-2724.

Hattori, K., Iverson, P. 2009. English /r/-/1/ category assimilation by Japanese adults: Individual differences and the link to identification accuracy. JASA 125, 469-479.

Takagi, N., Mann, V.A. 1995. The limits of extended naturalistic exposure on the perceptual mastery of English / $\mathrm{r} /$ and / / by adult Japanese learners of English. Applied Psycholinguistics 16, 379-405. 